\title{
Experimental investigation of erosion-corrosion phenomena in a steel fitting due to plain and slurry seawater flow
}

\author{
Mohamed Shehadeh ${ }^{1^{*}}$, Mohammed Anany ${ }^{2}$, Khalid M Saqr ${ }^{2}$ and Ibrahim Hassan ${ }^{3}$
}

\begin{abstract}
The present work presents an experimental characterization of the erosion-corrosion phenomena caused by confined slurry seawater flow. A set of experiments were conducted under a carefully controlled environment to estimate the erosion-corrosion severity in a $90^{\circ}$ pipe bend. Sand particle concentration ranged from 0 to $9 \mathrm{~g} / \mathrm{l}$. Accurate spectrometric measurements of eroded iron concentration in the drain flow were carried out in order to characterize the erosion-corrosion severity in the bend. Both the flow Reynolds number and sand particle concentration were directly correlated to the onset of erosion phenomena. Consequently, this study proposes empirical correlations to predict the erosion-corrosion rate as a function of sand concentration and Reynolds number with two sets of coefficients for both laminar and turbulent flow regimes.
\end{abstract}

Keywords: Slurry seawater; Erosion-corrosion; Laminar flow; Turbulent flow

\section{Review Introduction \\ Background and motivation}

Seawater systems (i.e. pipelines, elbows) are used by many industries, such as onshore/offshore oil and gas production, power plants and coastal industrial plants (Antaki 2003; Yang and Cheng 2012). The main use of seawater is for cooling purposes, but it is also used for fire fighting and oilfield water injection and in desalination plants (Kehr 2003). Nayyer (2000) describes pipeline networks as the arteries and veins of the modern civilization, since pipeline networks are implemented in fluid transmission and cooling purposes of either onshore or offshore applications. The widespread use of pipeline networks and their vast applications in oil and gas industries such as crude oil and natural gas transportation from production fields to refineries, processing plants and distribution to consumers explain the necessity of continuous monitoring and diagnosis of pipeline networks (Cronin 2000) in order to avoid catastrophic failures that can lead to grave environmental impacts. Many literatures have also discussed

\footnotetext{
* Correspondence: ezzfahmy@yahoo.com

${ }^{1}$ Marine Engineering Department, Arab Academy for Science, Technology and Maritime Transport, P.O.Box 2019, Abu Qir, Alexandria, Egypt

Full list of author information is available at the end of the article
}

the costly terms of production losses especially due to pipeline corrosion damages (Yang and Cheng 2012; Winkelmans and Wevers 2002; Kehr 2003; Roberge 2000).

Several structural as well as mechanical elements, such as elbows in pipeline networks and a ship's propeller churning in the ocean, can suffer from erosion-corrosion problems. Erosion-corrosion, also known as flow-assisted corrosion, is the general term encompassing a spectrum of mechanisms from accelerated corrosion to a purely mechanical damage, which causes high rates of material loss in industries (Elvis 2008; Roberge 2000; Chen 2006). In the former, moving liquid particles cause the damage, whereas collapsing (unstable) vapour bubbles induce surface damage in the latter (Roberge 2000). Fontana (1986) defines erosion as the acceleration or increase in rate of deterioration or attack on a metal because of the relative movement between a corrosive fluid and the metal surface. Generally, this movement is quite rapid, and mechanical wear effects or abrasion is involved. Erosion results in removal of the surface layer gradually in the form of small choppings (Chen 2006). Erosion-corrosion is characterized in appearance by grooves, gullies, waves and rounded holes and usually exhibits a directional pattern (Fontana 1986). The motion is usually one of high velocity, with mechanical wear and abrasion effects 
(Antaki 2003). Flow velocities influence the erosion behaviour; when the velocity of the flow increases, the rate of erosion-corrosion increases (Li et al. 2014; Roberge 2000; Yang and Cheng 2012).

\section{Erosion-corrosion detection and rate estimation}

Since the material selection process plays an important role in minimizing the erosion-corrosion damage, several environmental modifications can be implemented to minimize the risk of erosion failures (Li et al. 2014; Nivelle and Wang 2009; Nayyer 2000; $\mathrm{Hu}$ and Neville 2009; Sundararajan 1991). For example, Shedadeh et al. (2012) demonstrated that the detection of erosion enhances the overall system reliability and safety as well as the system performance. They have implemented acoustic emission techniques for monitoring pipeline networks in order to accommodate for the early detection of any abnormal behaviour of the system. However, the erosion-corrosion behaviour is affected by many parameters such as the flow velocity (Yang and Cheng 2012) and the solid particle contaminant concentration (Ansari et al. 2012). The flow velocity is widely studied because of its influence on the design process of freshwater/seawater systems subjected to corrosion effects (Nivelle and Wang 2009; Zheng et al. 2014; Roberge 2000; $\mathrm{Hu}$ and Neville 2009; Yang and Cheng 2012; Ansari et al. 2012). In general, the erosion-corrosion rate is estimated from the quantity of iron loss from the carbon steel of the pipeline system. Erosion-corrosion rate is given by the following expression:

$$
\text { Erosion-corrosion rate }=\frac{\mathrm{WL}}{A \times T},
$$

where WL is the iron loss weight (mg), $A$ is the elbow surface area $\left(\mathrm{m}^{2}\right)$ and $T$ is the time ( $\left.\mathrm{min}\right)$.

In the present paper, a series of laboratory experiments are carried out to study the behaviour of erosion-corrosion in carbon steel elbows. The elbows are connected to a plastic pipeline system filled with seawater contaminated with sand at three different concentrations running at various flow velocities covering the laminar and turbulent flow regimes.

\section{Experimental apparatus and procedure}

Elbows are considered the weakest part of a pipeline system, which are continuously subject to erosion-corrosion problems (Ansari et al. 2012; Keating and Nesic 1999). Hence, experiments are carried out on a set of four identical $90^{\circ}, 50.8-\mathrm{mm}$ carbon steel elbows with $2.8-\mathrm{mm}$ wall thickness. Low-carbon steel elbows were chosen due to their popularity and their broad usage in petroleum and fertilizer industries, power stations, shipbuilding and onshore and offshore platforms.

Figure 1 depicts a smooth and a clean inner surface of an elbow before starting the experiments. In order to

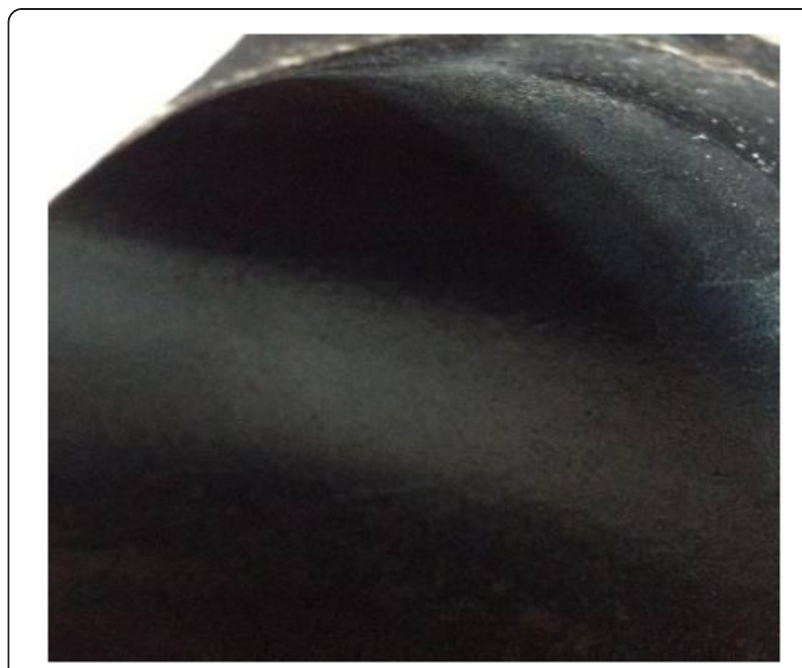

Figure 1 Internal surface of a new elbow.

assure correct results during iron losses, the entire components of the test rig were constructed of plastic apart from the carbon steel elbow under investigation. Highresistance polypropylene was chosen for the pipes and fittings due to its high resistance to salt and its chemical stability against wide ranges of temperatures. A plastic water tank and a stainless steel pump were also selected. Figure 2 illustrates the test rig construction.

The erosion-corrosion rates were calculated for flow regimes ranging from laminar, i.e. $\operatorname{Re}<2,300$, up to turbulent flow regimes of seawater at different levels of sand concentration. The Reynolds number calculations were based on the elbow inner diameter. The seawater density and dynamic viscosity were taken as $1,025 \mathrm{~kg} / \mathrm{m}^{3}$ and $0.0011 \mathrm{~kg} / \mathrm{ms}$, respectively (Guo et al. 2010).

Seawater was prepared at the laboratory by dissolving $35 \mathrm{~g}$ of salt in each litre of water following the recommendations of Culkin (1965). Direct usage of seawater is not recommended as it can contain uncontrollable concentrations of solid particles, which can also have harmful effects to the system.

Sand of an average grain size of $300 \mu \mathrm{m}$ was added to the prepared seawater at different concentrations. Sand was selected since many industrial processes which use seawater for cooling purposes receive the cooling water contaminated with sand. Also, sand is considered to posses the least harmful effects on the pump casing and its impeller.

Hach DR/2010 Spectrophotometer (Hach Company, Loveland, CO, USA) is a microprocessor-controlled, single-beam instrument for colorimetric testing in the laboratory or the field. This is used to measure the quantity of iron loss from the elbow in each sample of seawater. Also, FerroVer Iron Reagent (Hach Company) was used to determine the quantity of iron in seawater. 


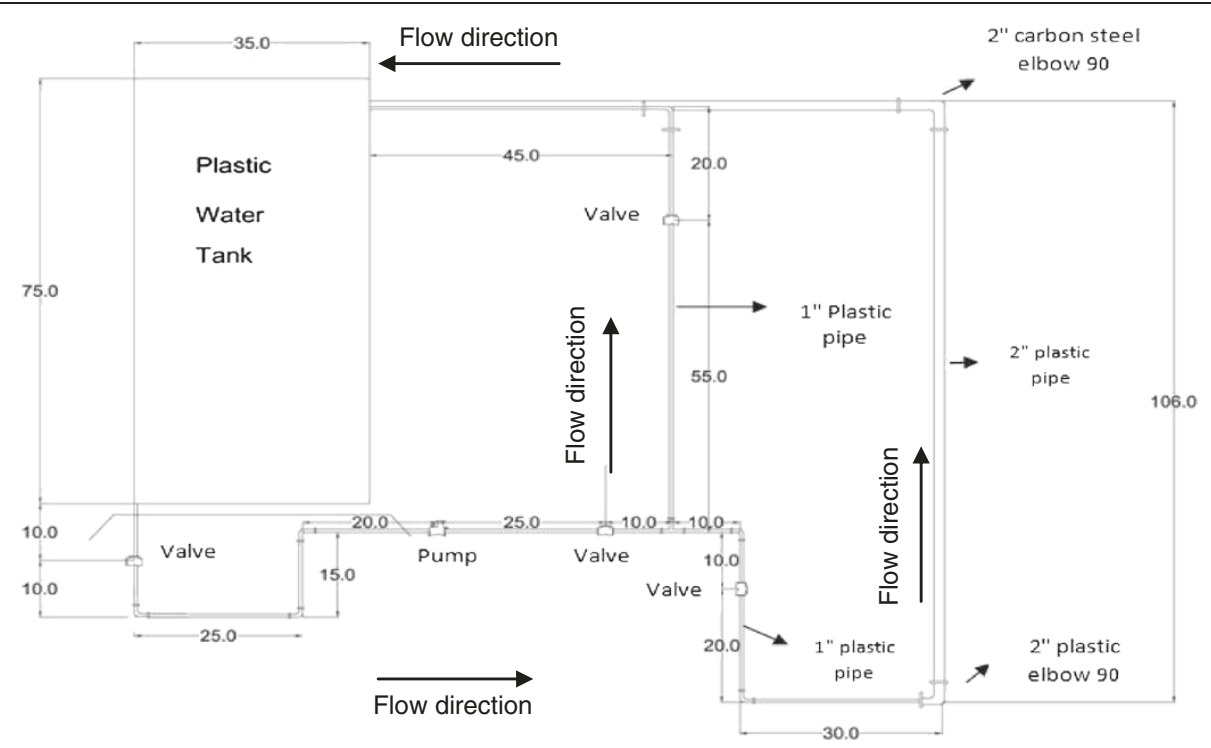

Figure 2 A schematic of the experimental system.

The pump and impeller materials were made from stainless steel to ensure that the ferrous ions in the solution are contributed from the carbon steel fitting only.

The erosion-corrosion analyses in these experiments were carried out for the determination of its rate in each elbow in the four different mediums by changing the velocity of the flow every $1 \mathrm{~h}$. A water sample of the outflowing water was collected every $20 \mathrm{~min}$ in a clean test tube which was initially washed with distilled water. Four elbows were tested in four different mediums (i.e. seawater and three sand concentrations).

In order to study the corrosion effect, a series of experiments was carried out with seawater only. Thereafter, for studying the erosion effect, 3, 6 and $9 \mathrm{~g} / \mathrm{l}$ of sand particles have been added to the seawater to obtain various effects of erosive environments that will predict the behaviour of erosion-corrosion rate in steel elbows. The experiments were conducted at a wide range of Reynolds number (582 to 25,922) covering laminar and turbulent flow regimes. Measurements were obtained at three time intervals of 20,40 and 60 min during the experimental runs.

\section{Results and discussion Iron weight losses}

Total weight loss tests were carried out on the carbon steel without the flow-induced solid particles (i.e. corrosion condition) and afterwards at three different solid particle concentrations in order to study the performance of carbon steel materials in erosive-corrosive mediums. Accordingly, the appropriate material loss models can be used in their range of applicability. Total weight loss of iron was measured for 40 min of operation of seawater as well as the weight loss for sand-contaminated seawater with sand concentrations of 3, 6 and $9 \mathrm{~g} / \mathrm{l}$ at different flow velocities. Iron weight losses in the case of uncontaminated seawater will be attributed to corrosion mechanisms.

However, the increase in weight losses due to sand contamination arises due to erosion effects. Figure 3 illustrates the normalized weight loss of iron against the flow velocity. For the turbulent flow regime, a significant increase in the weight loss is observed as the flow velocity is increased. Such behaviour was not observed in the laminar regime. Hence, it can be concluded that the flow velocity has no significant effect on erosion rates but only the sand concentration. On the other hand, in the turbulent flow, both sand concentrations as well as the flow velocity have significant effect on erosion.

Data given in Figure 3 can be expressed as follows:

$$
\ln \left(\frac{C}{C_{0}}\right)_{\mathrm{Fe}}=a_{1} \ln \operatorname{Re}+a_{2},
$$

where $C_{0}$ is the initial iron concentration in the water used for the experiment and was found to be equal to $1 \times 10^{-3} \mathrm{mg} / \mathrm{l}$ and $C$ is the iron concentration due to erosion-corrosion effects. The coefficients of Equation 2 are listed in Table 1.

\section{Effect of time and Reynolds number on erosion-corrosion rate}

The erosion-corrosion rate is affected by three main factors: concentration of sand, flow Reynolds number and time elapsed in the experiment. Figures 4, 5, 6 and 7 show contour plots of the erosion-corrosion rates to provide graphical illustrations of their dependence on such 


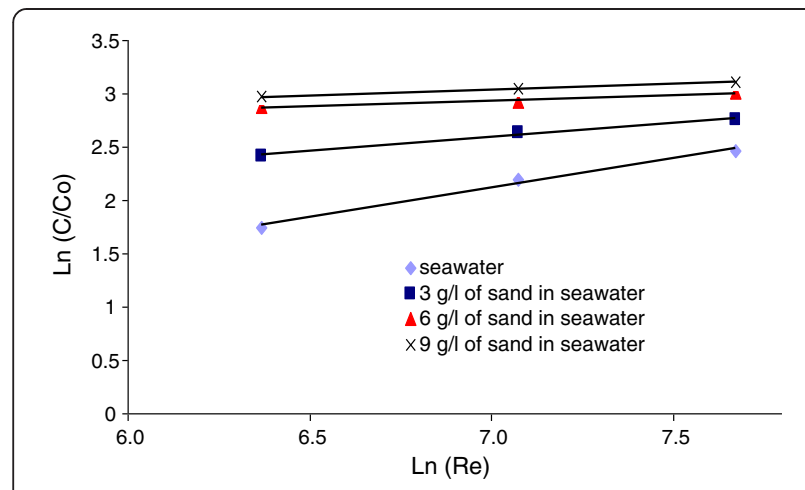

(a) Laminar

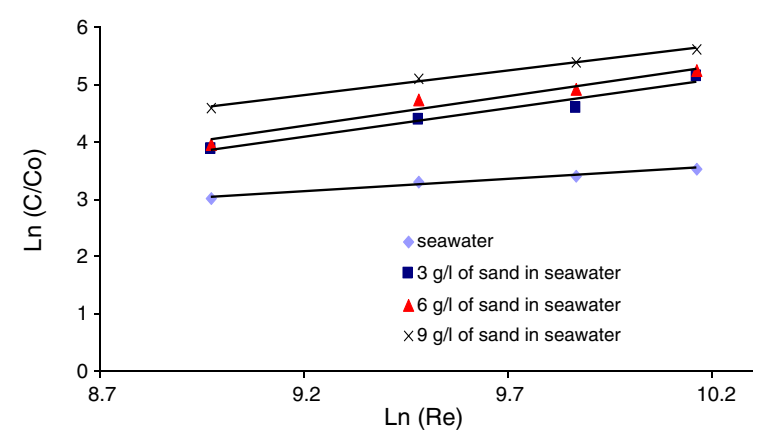

(b) Turbulent

Figure 3 Normalized weight losses vs Reynolds number at time $40 \mathrm{~min}$.

factors. The figures are results of time averaging the readings of erosion-corrosion rates over a wide range of Reynolds number. In plain seawater flow, as shown in Figure 4, the time dependence of corrosion is evidently higher than in turbulent flow. The corrosion rate increases approximately threefold when the Reynolds number increases 1 order of magnitude.

In slurry seawater flow, the Reynolds number still plays a more significant role in controlling the time dependence of erosion-corrosion phenomena rather than the concentration of sand particles, as depicted by comparing Figures 5, 6 and 7. In addition, the Reynolds number (i.e. flow regime) played a more significant role

\section{Table 1 Coefficients of Equation 2}

\begin{tabular}{lll}
\hline Flow regime & $\boldsymbol{a}_{\mathbf{1}}$ & $\boldsymbol{a}_{\mathbf{2}}$ \\
\hline $\begin{array}{l}\text { Uncontaminated } \\
\text { seawater (laminar) }\end{array}$ & 0.550 & -1.735 \\
$\begin{array}{l}\text { Uncontaminated } \\
\text { seawater (turbulent) }\end{array}$ & 0.420 & -0.735 \\
$\begin{array}{l}\text { Contaminated } \\
\text { seawater (laminar) }\end{array}$ & $0.009 C_{s}^{2}-0.137$ & $-0.078 C_{s}^{2}+1.190$ \\
Contaminated & $C_{s}+0.586$ & $C_{s}-2.085$ \\
seawater (turbulent) & $-0.011 C_{s}^{2}+0.114$ & $0.123 C_{s}^{2}-1.155$ \\
\hline
\end{tabular}

$\mathrm{C}_{\mathrm{s}}$ is the sand concentration in grams per litre.

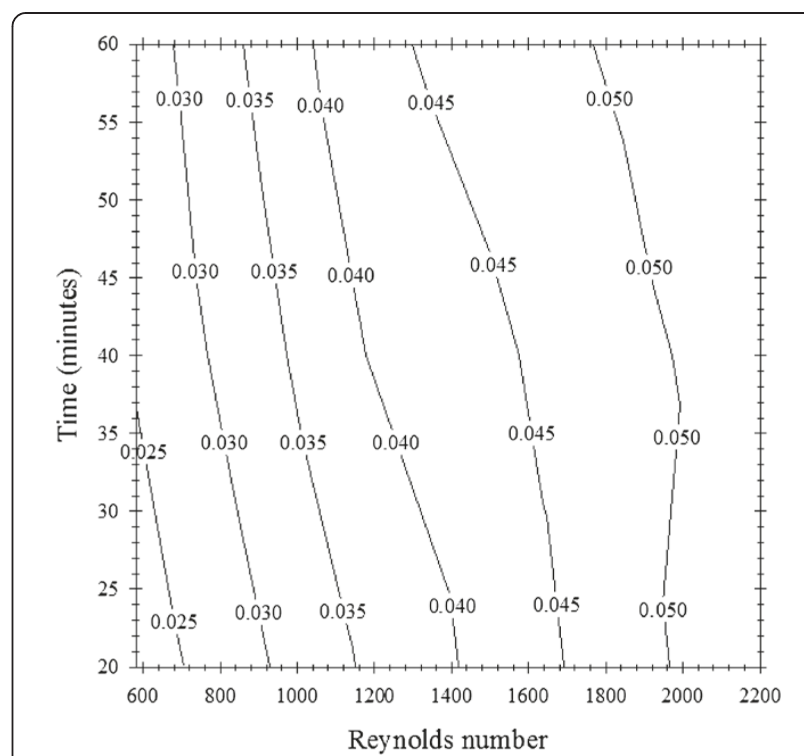

(a)

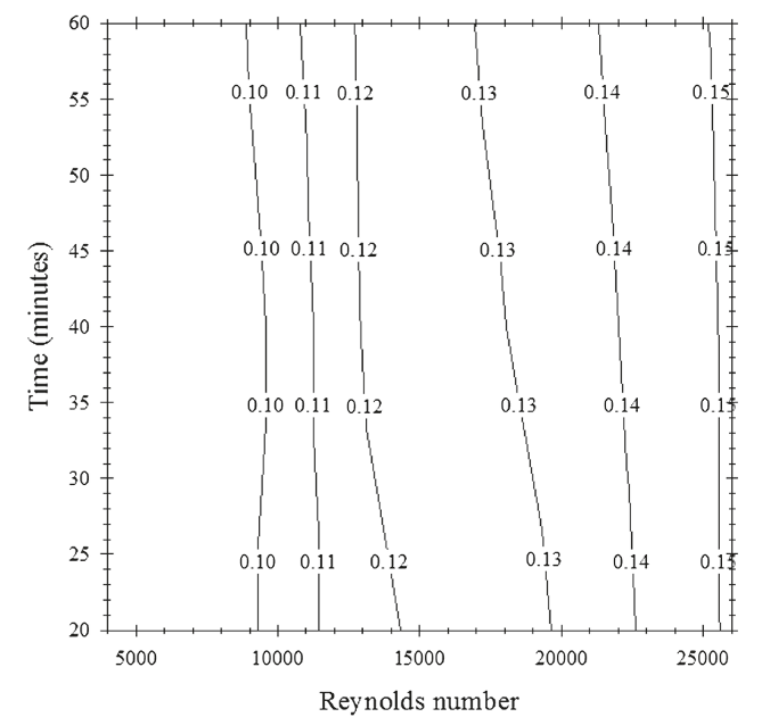

(b)

Figure 4 Temporal development of the corrosion rate $\left(\mathrm{mg} / \mathrm{m}^{2} /\right.$ min) for plain seawater. (a) Laminar and (b) turbulent flows.

in controlling the value of the erosion-corrosion rate rather than the sand concentration. When the sand concentration is doubled in laminar flow regime (Figures 5a and 6a), the erosion-corrosion rate exhibited an increase ranging from $20 \%$ to $35 \%$. When the former concentration was doubled in the turbulent flow regime and the Reynolds number was kept constant at $2.1 \times 10^{4}$, the rate increased by $25 \%$. On the other hand, when the sand concentration was kept constant at $6 \mathrm{~g} / \mathrm{l}$ and the Reynolds number was doubled from $1 \times 10^{4}$ to $2 \times 10^{4}$ in the turbulent flow regime, the erosion-corrosion rate was doubled. 


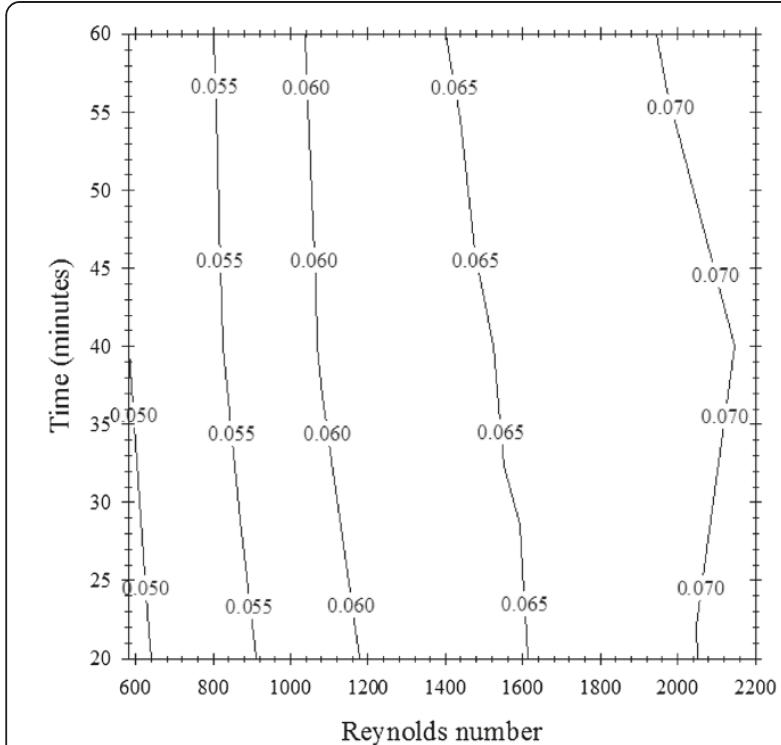

(a)

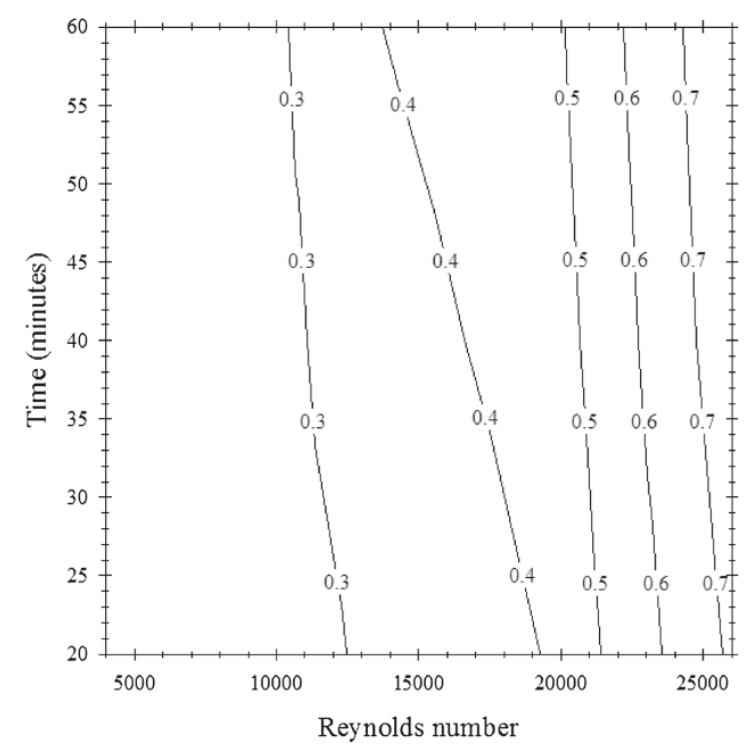

(b)

Figure 5 Temporal development of the erosion-corrosion rate ( $\mathrm{mg} / \mathrm{m}^{2} / \mathrm{min}$ ) for slurry seawater ( $3 \mathrm{~g} / \mathrm{l}$ sand concentration).

(a) Laminar and (b) turbulent flows.

Empirical correlations for predicting erosion-corrosion rate Analysis techniques are developed here to extract significant features of erosion-corrosion rate. The interest was given to develop empirical correlations to predict the erosion-corrosion rate as a function of the Reynolds number, based on the result presented in the 'Iron weight losses' section. Such results have manifested that the latter rate value is affected by the Reynolds number approximately four times than it is affected by sand concentration in both turbulent and laminar regimes. Hence, the erosioncorrosion rate was calculated using Equation 1 at all

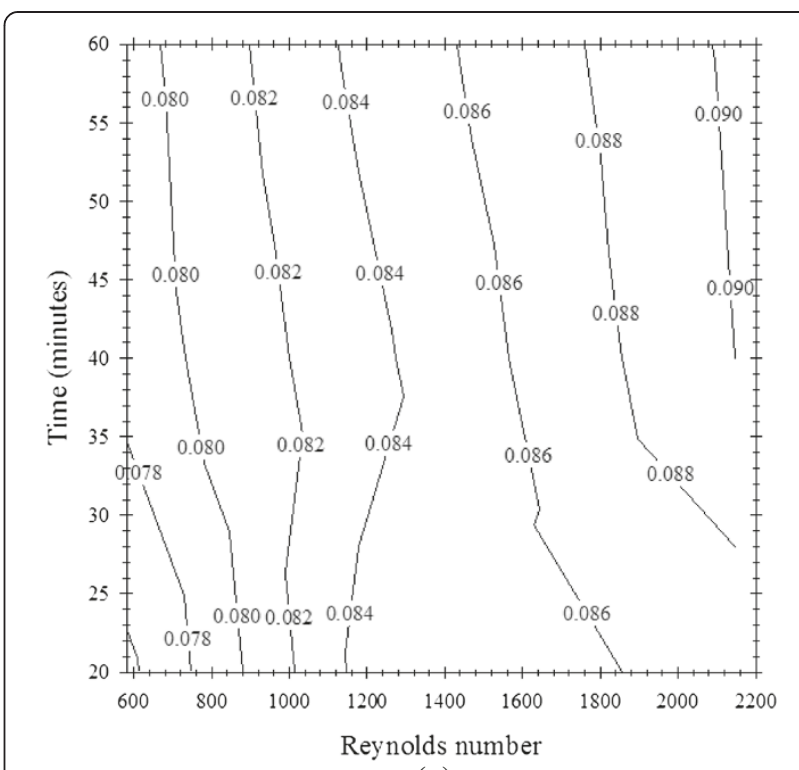

(a)

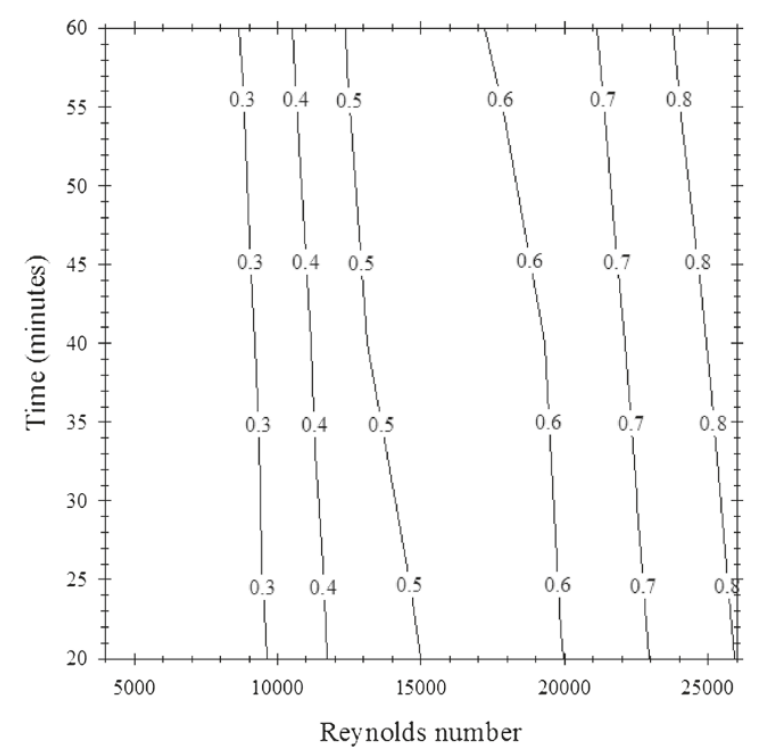

(b)

Figure 6 Temporal development of the erosion-corrosion rate ( $\mathrm{mg} / \mathrm{m}^{2} / \mathrm{min}$ ) for slurry seawater (6 $\mathrm{g} / \mathrm{l}$ sand concentration). (a) Laminar and (b) turbulent flows.

mediums for seven different velocities (i.e. Reynolds number) with 20-min increments. Figure 8 shows the erosioncorrosion rate of iron losses and individual contributors as a function of the sand concentration and Reynolds number. Figure $8 \mathrm{a}$ shows a linear relationship between the erosion-corrosion rate and the velocity for the flow for the laminar case with constant time after 40 min of operation in each velocity. Figure $8 \mathrm{~b}$ shows the same relation for the turbulent flow case.

From the observation of the trends at all mediums, it is clear that the increase of erosion-corrosion rate is very 


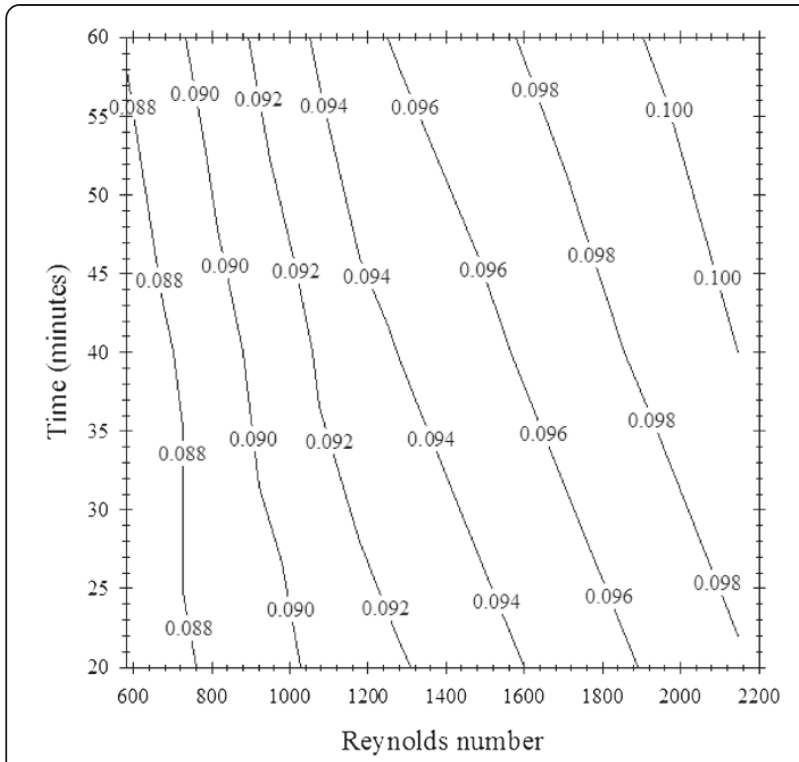

(a)

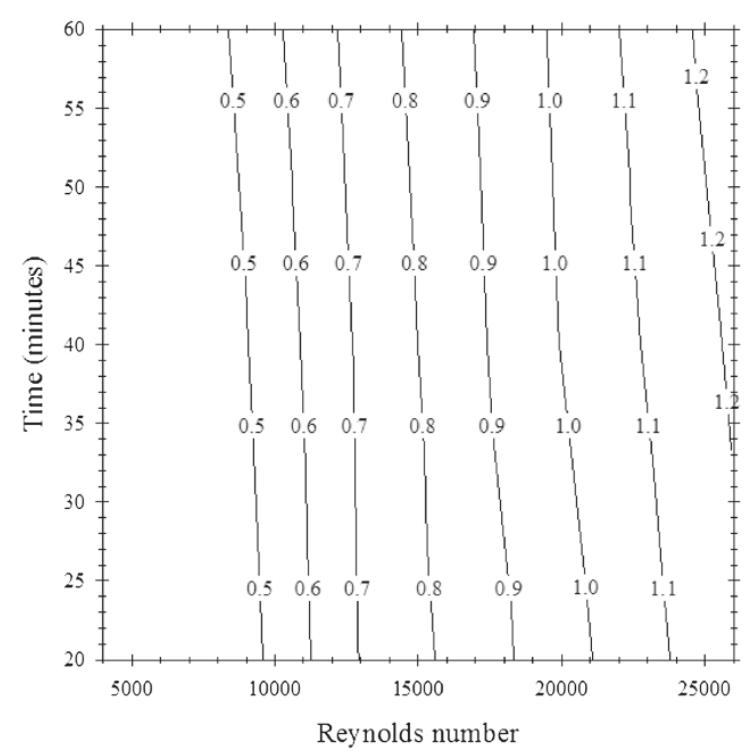

(b)

Figure 7 Temporal development of the erosion-corrosion rate ( $\mathrm{mg} / \mathrm{m}^{2} / \mathrm{min}$ ) for slurry seawater ( $9 \mathrm{~g} / \mathrm{l}$ sand concentration).

(a) Laminar and (b) turbulent flows.

high due to the change in the flow regime from laminar to turbulent, especially at seawater with $9 \mathrm{~g} / \mathrm{l}$ of sand at turbulent flow. However, for noncontaminated seawater, the increase of erosion-corrosion rate at turbulent flow is low, as shown in Figure 8b. The results here agreed with other researchers (e.g. Lu et al. 2011a; Hu and Neville 2009; Ansari et al. 2012; Yang and Cheng 2012). They have proven that the erosion-corrosion rate increases directly with increasing impact velocity of particles.

Figure 8 clearly indicates that there is great increase in erosion-corrosion rate by increasing the quantity of solid

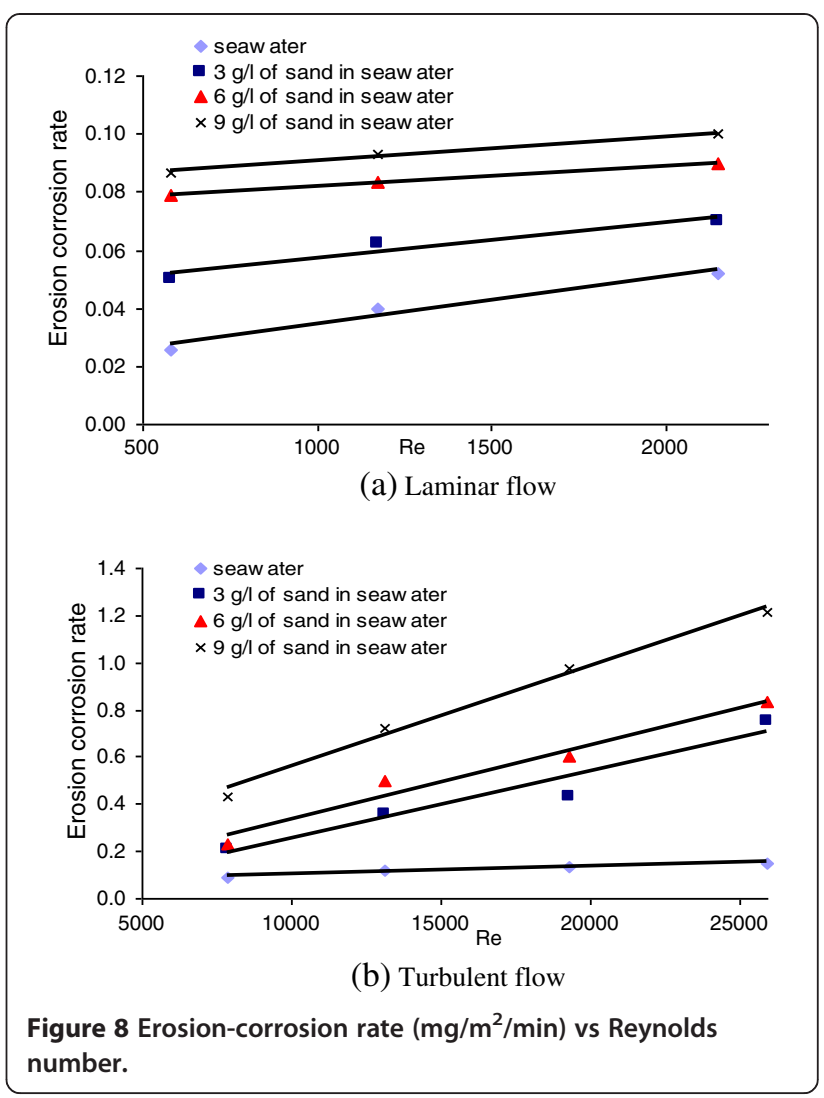

particles in seawater at laminar and turbulent flow regimes. The erosion-corrosion rate obeyed a linear relationship with the different flow regimes. The following equations for weight loss rates are proposed from the observed linear trends of Figure 8:

$$
\text { Erosion-corrosion rate }=b_{1} \operatorname{Re}+b_{2},
$$

where the coefficients $b_{1}$ and $b_{2}$ are constants for uncontaminated water, and functions in $\mathrm{C}_{\mathrm{s}}$ for contaminated water, where $C_{s}$ is the sand concentration in grams per litre. The values and functions are details in Table 2. The equations can help in the prediction of the erosioncorrosion rates based on the flow regime and solid particle concentrations for the range of the studied flow velocities.

\section{Internal surface condition}

To predict the condition of the internal surface of the elbow due to fluid containing solid particles, it is important to determine the qualitative conditions where erosioncorrosion becomes the dominant degradation process rather than flow-induced corrosion (Lu et al. 2011b). A highresolution camera was used to study the shape of the internal surface after $7 \mathrm{~h}$ of operation for each sand concentration. The erosion of the elbows is depicted in Figure 9.

For pure seawater and $3 \mathrm{~g} / \mathrm{l}$ sand (Figure 9a,b), corrosion is more eminent than erosion, whereas for sand concentrations of 6 and $9 \mathrm{~g} / \mathrm{l}$, traces of erosion are more 
Table 2 Coefficients of Equation 3

\begin{tabular}{lll}
\hline Flow regime & $\boldsymbol{b}_{\mathbf{1}}$ & $\boldsymbol{b}_{\mathbf{2}}$ \\
\hline $\begin{array}{l}\text { Uncontaminated } \\
\text { seawater (laminar) }\end{array}$ & $2 \times 10^{-5}$ & 0.016 \\
$\begin{array}{l}\text { Uncontaminated } \\
\text { seawater (turbulent) }\end{array}$ & $3 \times 10^{-6}$ & 0.730 \\
$\begin{array}{l}\text { Contaminated } \\
\text { seawater (laminar) }\end{array}$ & $\left(2 \mathrm{C}_{s}^{2}-30 \mathrm{C}_{\mathrm{s}}+200\right) \times 10^{-7}$ & $\left(-\mathrm{C}_{s}^{2}-21 \mathrm{C}_{s}-10\right) \times 10^{-3}$ \\
$\begin{array}{l}\text { Contaminated } \\
\text { seawater (turbulent) }\end{array}$ & $\left(6 \mathrm{C}_{\mathrm{s}}^{2}-5 \mathrm{C}_{\mathrm{s}}+4\right) \times 10^{-7}$ & $\left(2 \mathrm{C}_{\mathrm{s}}^{2}-5 \mathrm{C}_{\mathrm{s}}-41\right) \times 10^{-3}$ \\
\hline
\end{tabular}

obvious (Figure 9c,d). Hence, erosion effects were obvious for sand concentrations greater than $3 \mathrm{~g} / \mathrm{l}$ of sand in this type of elbows. This can be explained by the increase in erosion rate with velocity which is associated with the increase in kinetic energy of the erodent and number of sand impacts per unit time, causing more effective damage on the elbow metal surface. Since solid particles posses more inertia forces in comparison to seawater, they tend to fail to change their direction of motion within the elbow and hence hitting the outer bend side of the elbow. Hence, most of the erosion was observed to take place at this outer bend of the elbow which is in accordance with the work of Zeng et al. (2014), Keating and Nesic (1999) and Ansari et al. (2012).

\section{Conclusions}

In this work, the effect of seawater flow rate and seawater contamination level on erosion corrosion rates was investigated. Hence, four carbon steel elbows were tested at different sand contamination levels. The experiments were run to include both laminar and turbulent flow regimes. A plastic test rig was constructed allowing only for one carbon steel elbow to be tested at each time.

Within the chosen flow rates and contamination levels, it was found that the rates of erosion increase linearly with the increase of flow velocities and sand contamination levels. For this type of carbon steel elbows, it was found that $3 \mathrm{~g} / \mathrm{l}$ of sand is a critical concentration at which erosion mechanisms are observed. Generally speaking, the erosion rate was doubled on the transition from the laminar to the turbulent flow regime, whereas it is increased fourfold for seawater containing $9 \mathrm{~g} / \mathrm{l}$ of sand when the flow regime changed to turbulent. However, further investigation on different amounts of sand concentrations, solid particle size and material types needs to be carried out.

The study proposes a linear equation for predicting the erosion-corrosion rate with two sets of coefficients for both the laminar and turbulent flow regimes. Finally, these proposed empirical formulas could help in predicting erosion rates and pipeline design process.

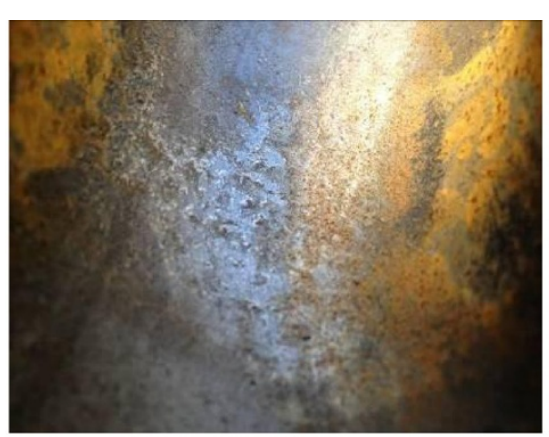

(a) Seawater

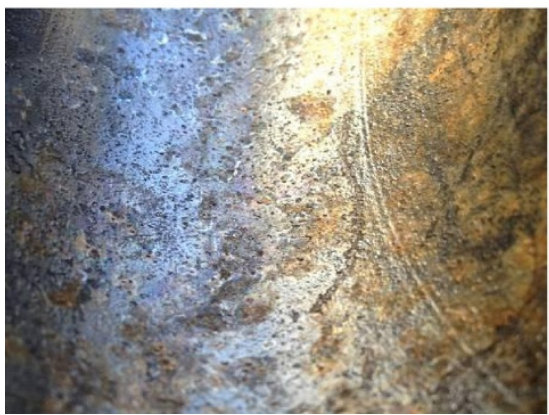

(c) $6 \mathrm{~g} / \mathrm{l}$ of sand

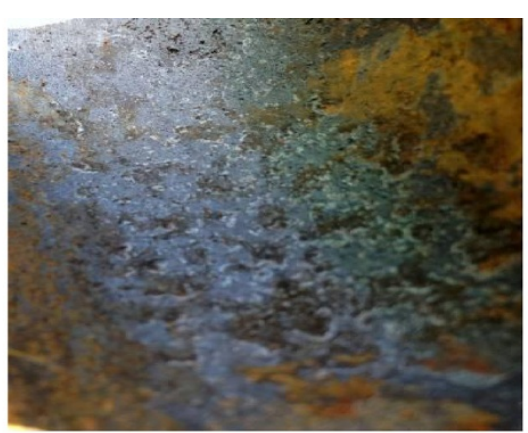

(b) $3 \mathrm{~g} / \mathrm{l}$ of sand

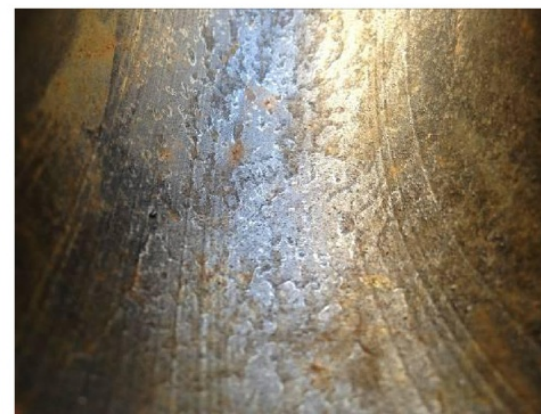

(d) $9 \mathrm{~g} / \mathrm{l}$ of sand

Figure 9 Internal elbow service after $7 \mathrm{~h}$ of operation in different sand concentrations. 


\section{Competing interests}

The authors declare that they have no competing interests.

\section{Authors' contributions}

MS contributed to the experimental design and measurements procedure. MA conducted the statistical analysis. KS participated in the data collection, interpretation and analysis. IH conducted the experimental measurements and data collection. All authors read and approved the final manuscript.

\section{Author details}

${ }^{1}$ Marine Engineering Department, Arab Academy for Science, Technology and Maritime Transport, P.O.Box 2019, Abu Qir, Alexandria, Egypt. ${ }^{2}$ Mechanical Engineering Department, Arab Academy for Science, Technology and Maritime Transport, P.O.Box 2019, Abu Qir, Alexandria, Egypt. ${ }^{3}$ Basic Studies (Chemical Engineering) Department, Arab Academy for Science, Technology and Maritime Transport, P.O.Box 2019, Abu Qir, Alexandria, Egypt.

Received: 28 April 2014 Accepted: 7 October 2014

Published online: 24 October 2014

\section{References}

Ansari, MR, Mohammadi, S, \& Oskouei, MK. (2012). Two-phase gas/liquid-solid flow modeling in $90^{\circ}$ bends and its effect on erosion. Global Journal of Researches in Engineering, 12(1), 35-44.

Antaki, GA. (2003). Piping and pipeline engineering (3rd ed.). USA: Taylor and Francis.

Chen, C. (2006). Interaction of chemical and mechanical effects in erosion-corrosion of pipeline steels in oil sand wastewater transportation, PhD thesis. USA: University of Alberta.

Cronin, DS. (2000). Assessment of corrosion defects in pipelines, Thesis. Ontario, Canada: University of Waterloo.

Culkin, F. (1965). The major constituents of seawater. Chemical Oceanography, 1, $121-161$.

Elvis, SR. (2008). Studies of corrosion and stress corrosion cracking behaviour of high-strength pipeline steels in carbonate-bicarbonate solutions, Thesis. Canada: University of Calgary.

Fontana, MG. (1986). Corrosion engineering (3rd ed.). USA: McGraw-Hill.

Guo, CQ, Zhang, CH, \& Paidoussis, MP. (2010). Modification of equation of motion of fluid-conveying pipe for laminar and turbulent flow profiles. Journal of Fluids and Structures, 26(5), 793-803.

$\mathrm{Hu}, \mathrm{X}$ \& \& Neville, A. (2009). CO2 erosion-corrosion of pipeline steel (API X65) in oil and gas conditions-A systematic approach. Wear, 267, 2027-2032.

Keating, A, \& Nesic, S. (1999). Prediction of two-phase erosion-corrosion in bends. In 2nd Conference on CFD in Minerals and Process Industries (CSIRO) (pp. 229-236). Melbourne, Australia: CSIRO.

Kehr, JA. (2003). Fusion-bonded epoxy internal linings and external coatings for 362 pipeline corrosion protection, Chapter B10. Piping Handbook, 7th Edition, M. Nayyar (ed.) Austin, Texas: NACA.

$\mathrm{Li}, \mathrm{JL}, \mathrm{Ma}, \mathrm{HX}$, Zhu, SD, Qu, CT, \& Yin, ZF. (2014). Erosion resistance of $\mathrm{CO}_{2}$ corrosion scales formed on API P110 carbon steel. Corrosion Science, 86, 101-107.

Lu, BT, Luo, JL, Guo, HX, \& Mao, LC. (2011a). Erosion-enhanced corrosion of carbon steel at passive state. Corrosion Science, 53(1), 432-440.

Lu, BT, Lu, JF, \& Luo, JL. (2011b). Erosion-corrosion of carbon steel in simulated tailing slurries. Corrosion Science, 53(3), 1000-1008.

Nayyer, ML. (2000). Piping handbook (7th ed.). USA: McGraw-Hill.

Nivelle, A, \& Wang, C. (2009). Erosion-corrosion of engineering steels—Can it be managed by use of chemicals? Wear, 267(11), 2018-2026.

Roberge, PR. (2000). Handbook of corrosion engineering. USA: McGraw-Hill.

Shedadeh, M, Hassan, I, Mourad, H, \& El-Gamal, H. (2012). Monitoring erosion-corrosion in carbon steel elbow using acoustic emission technique. In A Gallego \& K Ono (Eds.), 30th European Conference on Acoustic Emission Testing/7th International Conference on Acoustic Emission. Granada, Spain: University of Granada.

Sundararajan, G. (1991). A comprehensive model for the solid particle erosion of ductile materials. Wear, 149(1-2), 111-127.

Winkelmans, M, \& Wevers, M. (2002). Non-destructive testing for corrosion monitoring in chemical plants. Journal of Acoustic Emission, 20, 206-217.

Yang, Y, \& Cheng, YF. (2012). Parametric effects on the erosion-corrosion rate and mechanism of carbon steel pipes in oil sands slurry. Wear, 276-277, 141-148.
Zeng, L, Zhang, GA, \& Guo, XP. (2014). Erosion-corrosion at different locations of X65 carbon steel elbow. Corrosion Science, 85, 318-330.

Zheng, ZB, Zheng, YG, Zhoub, X, Hea, SY, Sunc, WH, \& Wangc, JQ. (2014). Determination of the critical flow velocities for erosion-corrosion of passive materials under impingement by $\mathrm{NaCl}$ solution containing sand. Corrosion Science, 88, 187-196.

doi:10.1186/s40712-014-0022-7

Cite this article as: Shehadeh et al: Experimental investigation of erosion-corrosion phenomena in a steel fitting due to plain and slurry seawater flow. International Journal of Mechanical and Materials Engineering 2014 9:22.

\section{Submit your manuscript to a SpringerOpen ${ }^{\odot}$ journal and benefit from:}

- Convenient online submission

- Rigorous peer review

- Immediate publication on acceptance

- Open access: articles freely available online

- High visibility within the field

- Retaining the copyright to your article

Submit your next manuscript at $\gg$ springeropen.com 